\title{
Desenvolvimento de jogos com uso de Pensamento Computacional e Aprendizagem Baseada em Projetos ${ }^{1 *}$
}

\author{
Jhoisnáyra V. R. de Almeida ${ }^{1}$, Marcos Vitor C. B. Nunes ${ }^{1}$, Francisco \\ Marcelino A. Almeida ${ }^{1}$ \\ ${ }^{1}$ Labiras - Instituto Federal do Piauí (IFPI) \\ Caixa Postal 198 - 64002-370 - Teresina - PI - Brasil \\ jhoisnayra.almeida@ifpi.edu.br,marcosvitorcastelo@gmail.com, \\ francisco.marcelino@ifpi.edu.br
}

\begin{abstract}
This article is an application of game development with Computational Thinking and Project Based Learning from creation of a game for Asteroids. In order to teach basic programming concepts, encourage the development of games and entry of students in the areas of computing.
\end{abstract}

Resumo. Neste artigo é apresentado o uso de desenvolvimento de jogos com Pensamento Computacional e Aprendizagem Baseada em Projetos a partir da criação de um jogo semelhante ao Asteroids. Com objetivo de ensinar conceitos básicos de programação, incentivar desenvolvimento de jogos e o ingresso de estudantes nas áreas de computação.

\section{Introdução}

O Pensamento Computacional é uma metodologia de resolução de problemas que dispõe de múltiplas características e requisitos que permitem aos alunos que o aderem ver uma relação entre diversos conteúdos acadêmicos. Entre os elementos que o pensamento computacional compreende, está inclusa segmentação de informações ou problemas em partes menores e administráveis, reconhecimento de padrões, identificação de fundamentos gerais que geram esses padrões e desenvolvimento de orientações passo a passo de como resolver impasses [Google 2017]. Dado que o pensamento computacional surgiu como um método de solucionar problemas, gerar sistemas e entender o comportamento humano que se constitui de conceitos primordiais da Ciência da Computação, sua finalidade para solução de problemas nas mais diversas áreas do conhecimento o torna uma competência fundamental para todas as pessoas, sendo assim, uma condição primária para a formação básica dos profissionais de todos os campos nos anos seguintes [Gomes 2013]. Uma outra metodologia educacional é a Aprendizagem Baseada em Projetos (PBL), que é um modelo de ensino que baseia-se em possibilitar que os alunos lidem com as obstáculos e as indagações do mundo atual que consideram interessantes determinando como abordá-los e, assim, agindo de modo cooperativo a fim de chegar em uma 
solução [Bender 2015]. A inserção de conceitos de Computação na Educação Básica é necessária por ter cunho colateral aos demais âmbitos do conhecimento. Nota-se a relevância de se desenvolver desde cedo habilidades como o Pensamento Computacional. Em países da Europa e nos Estados Unidos já há introdução de um currículo mínimo de Computação, entretanto, no Brasil, a discussão ainda é inaugural [De França 2013], apesar do uso de computadores ter sido presente no processo de ensino-aprendizagem desde a sua invenção [Joly 2002].

Este artigo apresenta o ensino de criação de jogos usando as metodologias de Aprendizagem Baseada em Projetos e Pensamento Computacional.

\section{Trabalho Proposto}

Atualmente, jogos se sobressaem não somente como um instrumento de puro entretenimento, mas também como um significativo artifício de ensino-aprendizagem [Gurgel 2006], pois a criação dos mesmos, abrange conceitos de programação e requer uso de lógica, necessitando de pesquisa e estudo para sua realização. A proposta deste projeto consiste no uso de uma ferramenta de desenvolvimento de jogos para aprendizagem de conceitos básicos de programação utilizando Aprendizagem Baseada em Projetos e Pensamento Computacional. Utiliza-se neste projeto o Game Maker Studio como mecanismo de desenvolvimento de jogos por ser uma ferramenta livre e acessível de criação de jogos 2D. Para aplicação das metodologias de PBL (Aprendizagem Baseada em Projetos) e CT (Pensamento Computacional), minicursos seriam ministrados por tutores que auxiliam os estudantes com uso de um material de aula que abrange todo o conteúdo para criação de um jogo.

Como consequência do minicurso apresentado, os alunos adquirem entendimento de conceitos básicos de programação, uma vez que o mini-curso abrange diversos conceitos de lógica e algumas sintaxes semelhantes à Linguagem $\mathrm{C}$.

Após a criação deste primeiro projeto, o aluno pode despertar o interesse pela área e ingressar na mesma, evoluindo, assim, o que foi estimulado por este projeto.

\section{Metodologia}

Para aplicação do projeto, foi utilizada a ferramenta de criação de jogos 2D, Game Maker Studio, que trabalha com a linguagem de programação denominada GML (Game Maker Language) e usa mecanismos de fácil procedimento para desempenho.

O projeto desenvolvido pelos alunos durante o minicurso foi um jogo semelhante ao Asteroids, criado em 1979 pela Atari. A escolha desse jogo se deu em razão da facilidade na sua criação e sua abrangência de assuntos na elaboração.

O minicurso tem duração de duas tardes seguidas, dividindo o conteúdo ministrado em duas partes apresentadas em um material didático de aula, 
acompanhado de monitores para auxiliar os alunos em impasses e ao final, os alunos conseguem obter um exemplo de jogo de Asteroids simples, apresentado na Figura 1.

O conteúdo abordado no minicurso abrange conceitos de criação de jogos, tais como: criação, divisão e organização de componentes do jogo (salas, sons, sprites, objetos e outros), configuração ou animação destes componentes, e sobretudo, programação dos mesmos, sistemas de vida e pontuação. O conteúdo explanado também contém concepções simples de programação, como: declaração de variáveis, uso de estamentos (if, else, while e outros), funções, herança e a lógica para desempenho do programa.

\section{Resultados}

A metodologia foi aplicada com um grupo de pessoas que foram inscritas previamente para participar do minicurso gratuito e aberto ao público no Instituto Federal, como mostra a figura 1. Essa aula foi realizada como preparação para a Global Game Jam, evento mundial no qual quaisquer pessoas interessadas se reúnem e formam grupos para criação de um jogo em 48 horas de forma colaborativa. O grupo de tutores e monitores foi composto de alunos do ensino médio do Instituto Federal, que ministraram a aula para o conjunto de participantes dos mais diversos níveis de estudo e faixa etária, entre eles alunos do ensino médio, alunos do ensino superior, professores e mestrandos. Com a ajuda dos monitores, os participantes tiveram seu primeiro contato com criação de jogos e desenvolveram, mesmo sem nenhum conhecimento prévio, o jogo de Asteroids completo.

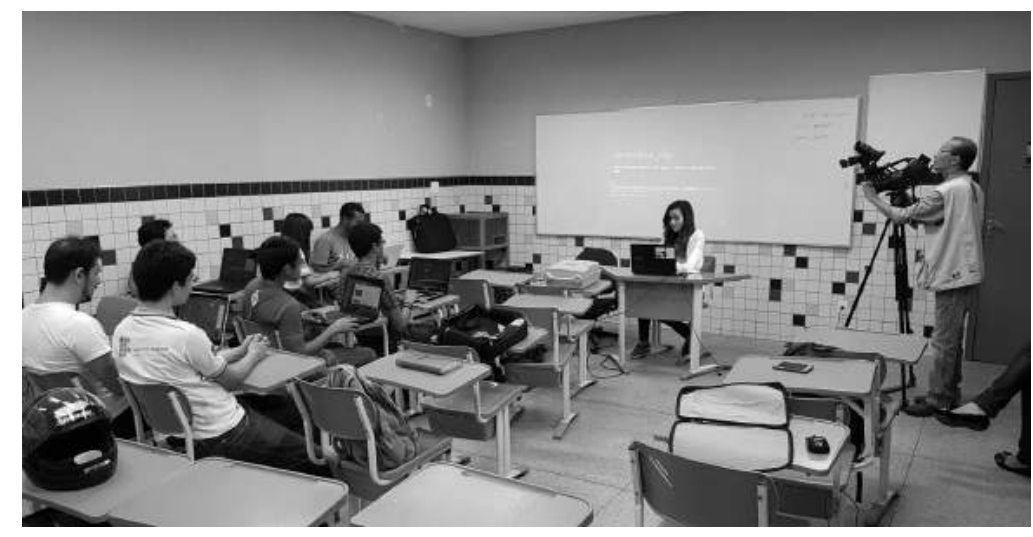

Figure 1. Aplicação do minicurso de jogos. Fonte: Autoria própria

O minicurso foi ministrado 2 dias antes do evento Global Game Jam, sediado no Instituto Federal do Piauí, os participantes do minicurso também se inscreveram no evento e durante ele desenvolveram jogos a partir do conhecimento adquirido [Labiras 2017]. Os jogos desenvolvidos foram submetidos e publicados no site oficial do evento [Global Game Jam 2017], nesse mesmo evento, em 2015, foi iniciado o Crown Brawl, jogo desenvolvido por alunos do IFPI e aceito na Imagine Cup 2017, campeonato mundial de tecnologia promovido anualmente pela Microsoft [IFPI 2017]. 


\section{Conclusão}

Como aspecto positivo dos resultados obtidos, se destaca o uso de recursos simples de produção e ensino. No entanto, a aplicação do minicurso foi limitada a poucos eventos e instituições, portanto, futuramente, espera-se levar este minicurso à outros lugares, em outras instituições (com foco nas instituições públicas e com acesso à laboratórios de informática), para que seja propagada a criação de jogos $2 \mathrm{D}$ acessível para todos. Pretende-se também criar uma apostila sobre criação de jogos, onde os alunos possam aprender de forma autônoma e, posteriormente, desenvolver projetos de autoria própria.

\section{Referências}

Ventura, Matthew et al. Development of a Video Game that Teaches the fundamentals of Computer Programming. In: SoutheastCon 2015. IEEE, 2015. p. 1-5.

Joly, Maria C. Rodrigues Azevedo. Tecnologia No Ensino: Implicações Para a. Casa do Psicólogo, 2002.

De França, Rozelma Soares; DO AMARAL, Haroldo José Costa. Proposta metodológica de ensino e avaliação para o desenvolvimento do pensamento computacional com o uso do scratch. In: Anais do Workshop de Informática na Escola. 2013. p. 179.

Google. 2017. Pensamento Computacional para Educadores . [ONLINE] Disponível em: https://computationalthinkingcourse.withgoogle.com/unit. [Acessado em 10 de março de 2017].

Gomes, T.; Melo, J. O Pensamento Computacional no Ensino Médio: Uma Abordagem Blended-Learning. In: Anais do XXI Workshop sobre Educação em Computação-XXXIII Congresso da Sociedade Brasileira de Computação. Maceió, AL-Brasil. 2013.

Bender, Willian N. Aprendizagem baseada em projetos: educação diferenciada para o século XXI. Penso Editora, 2015.

Gurgel, Ivannoska et al. A importância de avaliar a usabilidade dos jogos: A experiência do virtual team. Anais do SBGames, Recife, 2006.0

Global Game Jam. 2017. THE Game Jam Games. [ONLINE] Disponível em: http://globalgamejam.org/2017/jam-sites/game-jam/games. [Acessado em 26 de Abril de 2017].

Labiras. 2017. GLOBAL GAME JAM. [ONLINE] Disponível em: http://labiras.cc/ggj2017/. [Acessado em 26 de maio de 2017].

IFPI. 2017. Jogo criado no IFPI é finalista em competição de tecnologia da Microsoft. [ONLINE] Disponível em: http://libra.ifpi.edu.br/noticias/jogo-criado-no-ifpi-e-finalista-em-competicao-de -tecnologia-da-microsoft/view. [Acessado em 26 de maio de 2017]. 